\title{
Detailed Kinetic Modelling for Tar Species Evolution in a Downdraft Gasifier
}

\author{
Ahmed M. Salem ${ }^{1,2}$, Manosh C.Paul ${ }^{1}$ \\ ${ }^{1}$ Systems, Power \& Energy Research Division, School of Engineering, University of Glasgow \\ Glasgow, UK \\ Manosh.Paul@glasgow.ac.uk \\ ${ }^{2}$ School of Engineering, Tanta University \\ Tanta, Egypt \\ a.salem.2@research.gla.ac.uk
}

\begin{abstract}
Biomass is being used widely for energy production in various ways. One of the main schemes for energy production from biomass is gasification, and a powerful tool for optimising the behaviour of biomass gasifiers and also obtaining the required design for specific working conditions is the modelling. An integrated kinetic model was built by the authors ( [1], and [2]), which enabled to simulate, design and optimise the processes of downdraft biomass gasifiers for the production of high quality syngas. In the current research presented in this paper, the kinetic code has been extended by including detailed chemical mechanisms for the tar evolution and formation inside the gasifier. The model incorporated the evolution of 4 main tar species from pyrolysis to combustion and gasification with the formation and kinetic reaction rates of benzene, naphthalene, toluene, and phenol tar compounds. The effect of varying moisture content (MC) and equivalence ratio (ER) is studied to find out the optimum working conditions leading to the reduction of tar amount in the producer gas from downdraft gasifiers. The results reveals that moderate ER of 0.3 , with lower MC $<10 \%$, leads to the production of higher quality syngas with lower tar amounts.
\end{abstract}

Keywords: Biomass Gasification, Downdraft Gasifier, Kinetic Modelling, Syngas, Tar Reduction.

\section{Introduction}

One of the promising alternatives to fossil fuels is biomass. It is clean, renewable energy source, and environmentally friendly. Biomass can be converted into useful energy by gasification or into bio-oils through pyrolysis [3]. Particularly, biomass gasification is being used to convert biomass materials to useful gases (e.g. $\mathrm{CO}, \mathrm{H}_{2}$, and $\mathrm{CH}_{4}$ ), with some dilution gases $\left(\mathrm{N}_{2}\right.$, and $\left.\mathrm{CO}_{2}\right)$ and tar [4], and [5] which degrade the quality of the producer gases. Tar has a wide range of boiling points hydrocarbons that consists of one to five-ring aromatic hydrocarbons as reported by [6]. Generally tar can be defined as all hydrocarbons that have a molecular weight higher than benzene $\left(\mathrm{C}_{6} \mathrm{H}_{6}\right)$ and can be formed in hundreds of chemical compounds, but in most cases, about 20 species are present in significant amounts [7]. Finally, tar is a totally undesirable product from biomass gasification, as it can create many problems like condensation and plugging of downstream equipment [8].

Modelling is used to simulate gasifier behaviour at different working conditions. Researchers used equilibrium models [9], and [10] based on one global reaction mechanism to predict the product gas composition and gasification temperature at some extend. However, equilibrium models are less accurate compared to kinetic models, and it also gives an over prediction for the higher heating value and $\mathrm{H}_{2}$ output with lower amounts of $\mathrm{CO}$ [11]. On the other hand, kinetic models are used to overcome those problems and proved to be able to simulate a wider range of working parameters of a gasifier e.g. (producer gas composition, temperature distribution along gasifier, heating value and gasifier design ( [1], and [2]). Some other models were used to predict the tar formation during biomass gasification (e.g. see Ref. [12], [13], and [14]). Those models are usually standalone models which do not combine the gasification process and syngas production.

The current work is an extension of the existing kinetic model developed recently by the authors [1] - a four-zone integrated kinetic model used a novel approach which optimises the reduction zone length to predict the gas composition and temperature along a gasifier with a total amount of tar. The model also used to optimise the gasifier design based on the 
working conditions and feedstocks used. Tar was assumed to be having one compound represented by formula $\left(\mathrm{C}_{6} \mathrm{H}_{6.62} \mathrm{O}_{0.2}\right)$. The current research presents an extension of the kinetic code to study the specific tar species evolution and formation along the gasifier height. 4 main tar species will be traced from devolatilization trough oxidation and reduction zones. When designing a gasifier, a well understanding of the tar and different gas species formation and kinetic reactions, and the effect of working parameters on them, should be of a high importance. The model will be further used to optimise the design of a gasifier to produce a higher quality producer gas (higher HV, and lower tar content) based on a sensitivity analysis depending on varying MC and ER. To the best of our knowledge, there is no other kinetic model that includes tar formation tracked from each zone, and how they influence on the production of different gas species along the gasifier height at different zones.

\section{Tar Species Modelling}

Tars can be classified as primary, secondary, and tertiary [6] depending on many factors. Pyrolysis products mainly yield primary tars (e.g. phenol, and acetol) and condensable molecules at a temperature under 973K. During oxidation and gasification, and at higher temperatures, primary tars tend to be converted to secondary and tertiary tars (e.g. benzene, naphthalene, acenaphthylene and pyrene) [12]. Primary tars formed during pyrolysis are composed of more than 100 species, yet their formation and kinetic rats are not well known. So, the model will use simplified compounds representing each group by studying the rate kinetics of four main tar species (benzene, naphthalene, toluene, and phenol). Phenol can represent primary tars. Toluene is the best representative for secondary tars, while benzene and naphthalene as a PAH represent tertiary tars. The four compounds were also found to represent (70-95)\% of the tar species formed during biomass gasification, so modelling those species will help to mimic the tar formation in a downdraft gasifier.

\section{1. Pyrolysis Tar Formation}

After drying, and while temperature increases, biomass starts to decompose into volatiles, char and tar. Tar decomposition in pyrolysis is addressed based on [14] who reported parameters for the empirical correlations of pyrolysis products based on the experimental data taken from [15]. The results give the mass yield of tar evolution during the pyrolysis process in $\mathrm{g} \mathrm{tar} / \mathrm{kg}$ biomass. More details of pyrolysis tar formation in the current model are stated in [16].

\section{2. Combustion and Reduction Zones: Tar formation and destruction}

Pyrolysis products are used as a feed for the combustion zone. The reactions in combustion and reduction zones are based on the kinetic rate reactions stated in [16]. The model incorporates 18 different kinetic reactions, between volatile gases and tar species. All reactions take place after the energy balance to estimate the exact temperature of each zone through a backward calculation.

\section{Results and Discussions}

The model is first validated, and then further used to study the effect of working parameters on the tar formation.

\section{1. Model Validation}

Due to the lack of data about tar species formed in downdraft gasifiers, the model validation is currently limited to the mass balance calculations. However, the work is underway for the further validation and assessment against experiment being carried out by the authors at KHT institute, Sweden. Nevertheless, the total tar produced by the model was already verified at [16] and found to be in very good agreement with experimental data.

Fig. 1 shows the mass balance calculation results derived from the kinetic code for rubber wood used as feedstock at different equivalence ratios with a constant moisture content of $10 \%$. Total mass input including biomass and air is calculated and mass output for the producer gas and tar species is added as well. The results tend to be fair and prove the model stability at different working conditions. 


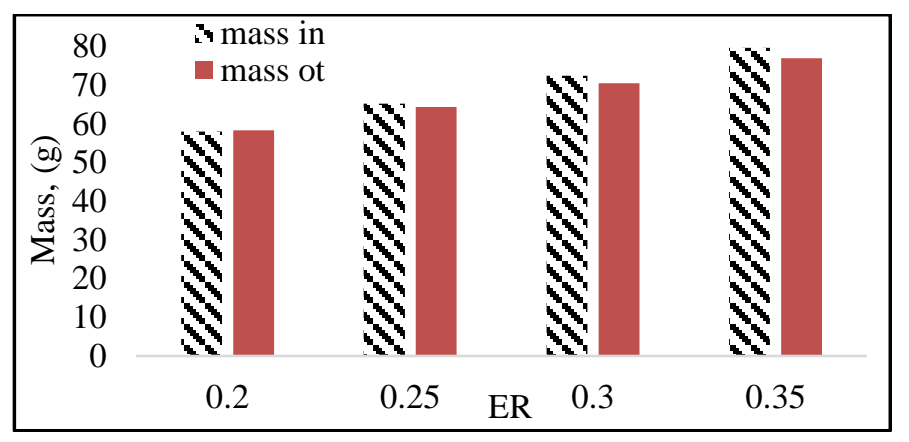

Fig. 1: Mass balance between input and output for Rubber wood gasification.

\section{2. Tar Formation along Gasifier Height}

The set of results shown in Fig. 2 illustrates the distribution of different tar species along the gasifier height. Again rubber wood feedstock was used in this case with a fixed $\mathrm{MC}$ of $10 \%$, and the effect of varying ER was studied. Increasing ER results in a significant increase of temperature and hence increases the reaction rates of combustion zone, which further leads to the tar destruction and consequently, decreases the tar amount as shown.
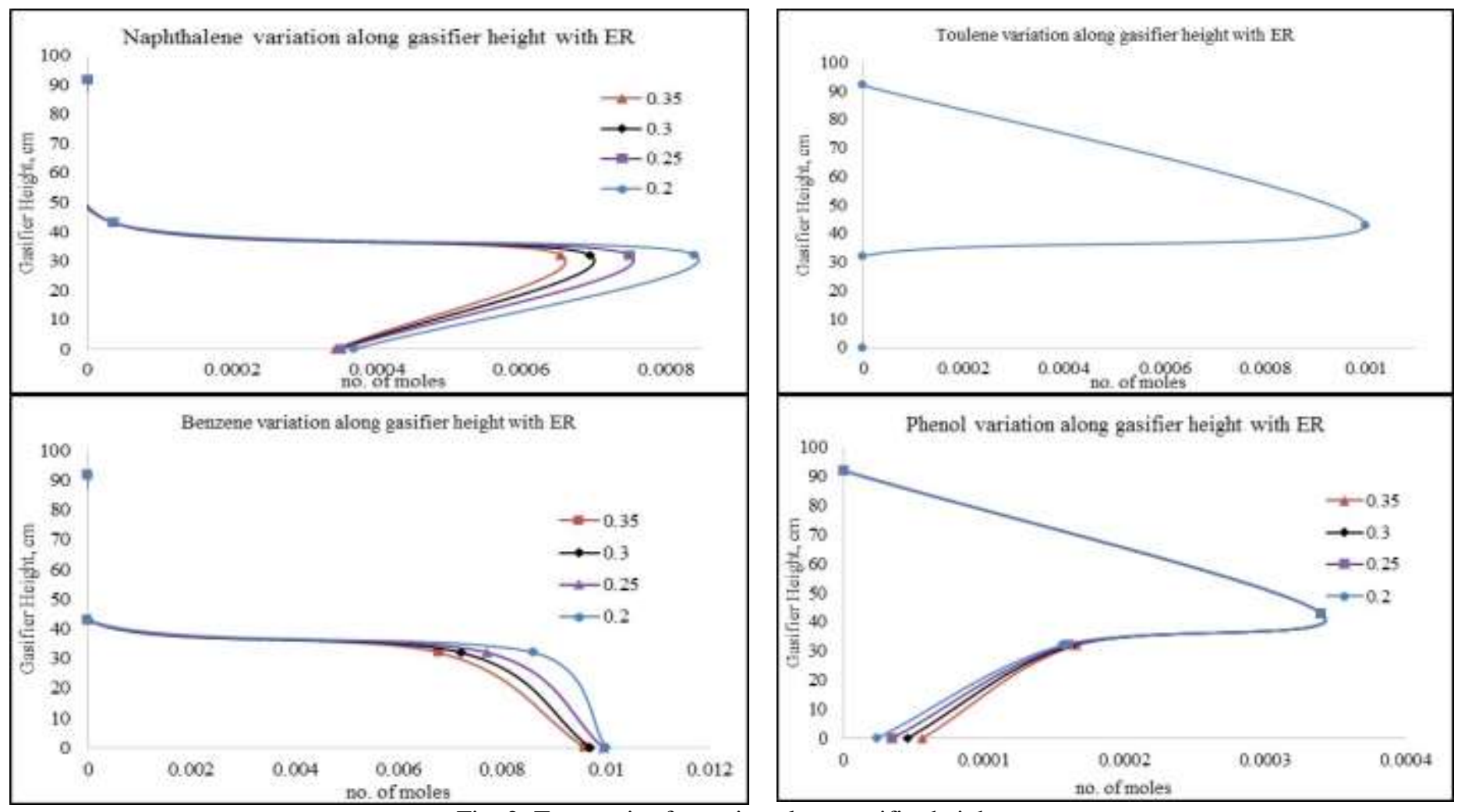

Fig. 2: Tar species formation along gasifier height.

Toluene and phenol show having a small variation and tend to be found in very small amounts, because both are primary tars. Primary tars tend to be converted into secondary and tertiary tars while temperature increases above 773 K [17]. Temperature profile of this case was discussed in [16], and showed that the combustion temperature was around 1350K. On the other hand, naphthalene is found in a considerable amount and shows a decrease with temperature and ER increase. Naphthalene also tends to be converted into $\mathrm{C}, \mathrm{CO}, \mathrm{H}_{2}$, and benzene based on the reactions stated in [16]. Overall, benzene shows the highest portion of tar species based on [15], and [13], and usually greater than $37 \%$ by weight of total tars produced 
[8]. The higher amounts of both benzene and naphthalene are mainly due to primary and secondary tars conversion in oxidation and reduction zones. Furthermore, both require higher temperatures $(>1600 \mathrm{~K})$ to start cracking, and the oxidation temperature is usually lower than this value. The result shows good agreement with previous works and thus further proves the model's capability and stability over changing working parameters. Sensitivity analysis also is carried out and showed that moderate ER of 0.3 , with lower $\mathrm{MC}<10 \%$, leads to the production of higher quality syngas with lower tar amounts.

\section{Conclusion}

A detailed kinetic model for specific tar species formation along downdraft gasifiers was built. The model incorporates 4 main tar species; benzene, naphthalene, toluene and phenol, which covers all the categories of tar compounds. The model was successfully verified with previous works, and results presented showed the evolution and distribution of tar species along gasifier zones with different working conditions. Sensitivity analysis was carried out and ER $\sim 0.3$ and MC $~ 10 \%$ resulted the production of lower tar amounts with higher quality syngas. Furthermore, the authors are working on new techniques towards an effective tar destruction method in downdraft gasifiers.

\section{Acknowledgements}

The first author would like to thank The Egyptian Cultural Affairs and Missions Sector and the British Embassy in Egypt for funding his $\mathrm{PhD}$ research study at the University of Glasgow. The second author (M. C. Paul) also acknowledges his RAEng/The Leverhulme Trust Senior Research Fellowship support (LTSRF1718\14\45) from the Royal Academy of Engineering, UK.

\section{References}

[1] A. M. Salem, and M. C. Paul, "An integrated kinetic model for downdraft gasifier based on a novel approach that optimises the reduction zone of gasifier," Biomass and Bioenergy, vol. 109, pp. 172-181, 2018.

[2] A. M. Salem, U. Kumar, A. N. Izaharuddin, H. Dhami, T. Sutari, and M. C. Paul, "Advanced numerical methods for the assessment of integrated gasification and CHP generation technologies," in Coal and Biomass Gasification, Energy, Environment, and Sustainability. Springer, 2018, pp. 307-330.

[3] P. Basu, Biomass Gasification, Pyrolysis, and Torrefaction. Practical Design and Theory, $2^{\text {nd }}$ Ed. Amsterdam: Academic Press, 2013.

[4] A. M. Sepe, J. Li, and M. C. Paul, "Assessing biomass steam gasification technologies using a multi-purpose model," Energy Conversion and Managment, vol. 129, pp. 216-226, 2016.

[5] L. Yan, Y. Cao, and B. He, "On the kinetic modeling of biomass/coal char co-gasification with steam," Chemical Engineering Journal, vol. 331, pp. 435-442, 2018.

[6] A. M. Ahmed, A. Salmiaton, T. S. Y. Choong, and W. A. K. WanAzlina, "Review of kinetic and equilibrium concepts for biomass tar modeling by using Aspen Plus," Renewable and Sustainable Energy Reviews, vol. 52, pp. 1623-1644, 2015.

[7] C. M. Kinoshita , Y. Wang, J. Zhou, "Tar formation under different biomass gasification conditions," Journal of Analytical and Applied Pyrolysis, vol. 29, pp. 169-181, 1994.

[8] P. Basu, Biomass Gasification, Pyrolysis, and Torrefaction. Practical Design and Theory. Second Edition, Amsterdam: Academic Press, 2013.

[9] A. Melgar, J. F. Pe'rez, H. Laget, and A. Horillo, "Thermochemical equilibrium modelling of a gasifying process," Energy Conversion and Management, vol. 48, pp. 59-67, 2007.

[10] P. P. Dutta,V. Pandey, A. R. Das, S. Sen, and D. C. Baruah., "Down Draft Gasification Modelling and Experimentation of Some Indigenous Biomass for Thermal Applications," Energy Procedia, vol. 54, pp. 21 - 34, 2014.

[11] Li XT, J. R. Grace,C. J. Lim, A. P. Watkinson, H.P. Chen, and J. R. Kim, "Biomass gasification in a circulating fluidized bed," Biomass and Bioenergy, pp. 171-193, 2004.

[12] P. Morf, P. Hasler, and T. Nussbaumer, "Mechanisms and kinetics of homogeneous secondary reactions of tar from continuous pyrolysis of wood chips," Fuel, vol. 81, pp. 843-853, 2002. 
[13] A. Fourcault, F. Marias, and U. Michon, "Modelling of thermal removal of tars in a high temperature stage fed by a plasma torch," biomass and bioenergy, vol. 34, pp. 1363-1374, 2010.

[14] A. Dufour, L. Abdelouahed, O. Authier, G. Mauviel, J. P. Corriou, and G. Verdier, "Detailed Modeling of Biomass Gasification in Dual Fluidized Bed Reactors under Aspen Plus," Energy and Fuels, vol. 26, pp. 3840-3855, 2012.

[15] A. Dufour, E. Masson, P. Girods, Y. Rogaume, and A. Zoulalian, "Evolution of Aromatic Tar Composition in Relation to Methane and Ethylene from Biomass Pyrolysis-Gasification," Energy Fuels, vol. 25, pp. 4182-4189, 2011.

[16] A. M. Salem, U. Kumar, and M. C. Paul, "Kinetic Modelling for Tar Evolution and Formation in a Downdraft Gasifier," in World Congress on Engineering, London, UK, 2018, pp. 800-805.

[17] P. Basu, Biomass gasification and pyrolysis: practical design and theory. Burlington: Academic press, 2010. 